\title{
Strain rate effects on mechanical properties of Fe-10Mn-5Al-0.5C steel
}

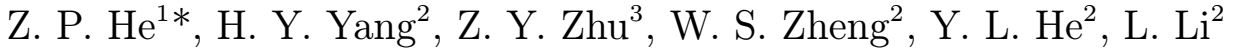 \\ ${ }^{1}$ School of Mechanical Engineering, Chengdu University, Chengdu 610106, P. R. China \\ ${ }^{2}$ School of Materials Science and Engineering, Shanghai University, Shanghai 200072, P. R. China \\ ${ }^{3}$ Advanced Research Institute, Chengdu University, Chengdu 610106, P. R. China
}

Received 28 December 2019, received in revised form 27 June 2020, accepted 30 June 2020

\begin{abstract}
The tensile deformation behavior of Fe-10Mn-5Al-0.5C steel was studied in an extensive range of strain rate $\left(0.001-1200 \mathrm{~s}^{-1}\right)$. The results show that the steel has high strength $(886 \mathrm{MPa})$ and plasticity $(41 \%)$ and exhibits excellent combinations of specific strength and ductility $(>36,000 \mathrm{MPa} \%)$ at the strain rate of $0.001 \mathrm{~s}^{-1}$. With the increase of strain rate from 0.001 to $1200 \mathrm{~s}^{-1}$, the tensile strength of the steel was increased from 886 to $1015 \mathrm{MPa}$, while its elongation first decreased from 41 to $16 \%$, and then increased from 16 to $25 \%$. At the strain rate of $450 \mathrm{~s}^{-1}$, the elongation is minimal, and the energy absorption capacity is the lowest. With the deformation progresses, the value of $n$ increases from small to large, the strain hardening effect becomes high.
\end{abstract}

K e y w o r d s: strain rate, mechanical properties, Fe-Mn-Al-C steel, retained austenite

\section{Introduction}

Fe-Mn-Al-C steels allow high-density reduction about $\sim 18 \%$ lighter than conventional steels, high corrosion resistance, high strength (ultimate tensile strength $\sim 1 \mathrm{GPa}$ ), and at the same time ductility above $60 \%$ [1], which have many potential applications in the field of advanced transportation systems, wear parts, shape memory alloys, and biomaterials, especially in automotive and powertrain systems. This has caused great interest in the automotive armor, mining, and steel industries. The mechanical properties of the Fe-Mn-Al-C steels can be modified by the control of the deformation mechanisms: transformation plasticity (TRIP), twinning-induced plasticity (TWIP), slip dislocations, and microband-induced plasticity (MBIP) induced. The activation of different deformation mechanisms is intimately related to the stacking fault energy (SFE) of austenite, and the SFE depends on factors such as chemical composition, the grain size of austenite, and deformation temperature $[2-5]$. However, the combination of strength and ductility (i.e., tensile strength $(\mathrm{TS}) \times$ elongation) of TRIP steels is mostly in the range of $15,000-25,000 \mathrm{MPa} \%$.
It still cannot cope with the recent soaring fuel costs and stricter safety and carbon dioxide emissions regulations. TWIP steels have a tensile strength of about $900 \mathrm{MPa}$ and a ductility of more than $50 \%$, which can meet the needs of such machinery. But TWIP steels are poor in weight reduction because the atomic weight of manganese, the main alloying element of TWIP steels, is comparable to that of iron. In contrast, the alloying content of light elements such as aluminum is low.

Recent studies [6-9] show that increasing the $\mathrm{Al}$ content to about $9 \%$ in high-manganese austenitic steels not only reduces the weight significantly but also obtains the mechanical properties equivalent to TWIP steels. These effects are mainly due to the increase of stacking fault energy (SFE) in the high-manganese austenitic steel with increasing $\mathrm{Al}$ content, and the deformation mechanism from the TWIP mechanism to the dislocation slip mechanism $[10,11]$. However, most of the studies were concentrated on the mechanical behavior and microstructure change of Fe-Mn-Al-C steels under static tension loading conditions. But the automobile steel body parts are manufactured by forming with the deformation rate in the process be-

*Corresponding author: e-mail address: sduhzp@hotmail.com 
Table 1. Chemical composition (wt.\%) and the heat treatment process of the steel tested

\begin{tabular}{ccccc}
\hline $\mathrm{C}$ & $\mathrm{Mn}$ & $\mathrm{Al}$ & $\mathrm{Fe}$ & Heat treatment process \\
\hline 0.5 & 10 & 5 & Bal. & $850^{\circ} \mathrm{C} \times 5$ min + water quenching \\
\hline
\end{tabular}

ing between $10^{-1}$ and $10 \mathrm{~s}^{-1}$. The deformation rate of the material during the impact on the vehicle is in the range of $10^{2}$ to $10^{3} \mathrm{~s}^{-1}$. Therefore, to utilize more Fe-Mn-Al-C steels in automobiles effectively, it is necessary to understand their mechanical behavior and microstructure evolution under high-speed deformation conditions.

In general, the studies on dynamic deformation of Fe-C-Mn-Al system steels were mainly focused on TRIP and TWIP steels [12-15]. Tang et al. [12] studied the dynamic behavior of Fe-15Mn-3Al-0.23C TRIP/TWIP steel. They indicated that the strain rate had no significant effect on the TRIP effect, and deformation twinning was the primary deformation mechanism with the increase of strain rate from 7 to $700 \mathrm{~s}^{-1}$. Park et al. [13] investigated the quasi-static and dynamic deformation mechanism of Fe-15Mn-1.2Al-0.6C TWIP steel. They demonstrated that the TWIP steel showed higher strength and similar ductility under dynamic loading because of the favorable effect of the increased planar slip and twinning on tensile properties. Curtze et al. [14] indicated that adiabatic temperature increase led to a change in stacking fault energy, shifting $\gamma_{\mathrm{SFE}}$ either towards or away from the optimum value for twinning. Ha et al. [15] pointed out that under high strain rate deformation, there is a formation of nanostructure austenite in TWIP steel, due to the occurrence of deformation twinning forming nanoscale twin/matrix lamellae followed by dynamic recovery induced by adiabatic heating. However, up to date, there are relatively few studies on microband induced plasticity (MBIP) Fe-Mn-Al-C steels, especially in high strain rate conditions. Considering the complexity of the influence of strain rate on the deformation behavior and mechanical properties of MBIP Fe-Mn-Al-C steels, the deformation mechanisms of the MBIP FeMn-Al-C steels during dynamic deformation are not clear. Therefore, it is necessary to study the influence of strain rate on the dynamic behavior of MBIP Fe-Mn-Al-C steels.

In this study, a new type of MBIP Fe-Mn-Al-C steel has been designed. The addition of $\mathrm{Al}$ reduces the density of the steel. The current work is to explore microstructural evolution, mechanical properties and deformation behavior of Fe-10Mn-5Al-0.5C steel under the loading in a range of strain rates $0.001-$ $1200 \mathrm{~s}^{-1}$, to understand the effects of strain rate on adiabatic temperature rise, SFE, deformation mechanisms, and mechanical properties of Fe-10Mn-5Al$-0.5 \mathrm{C}$ steel.

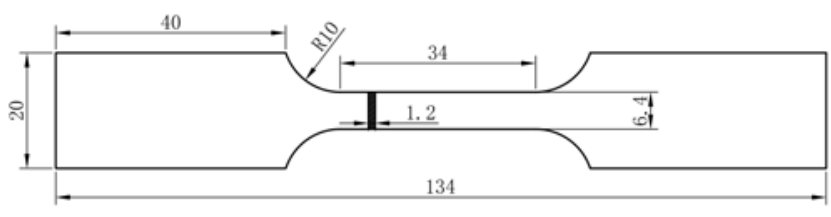

Fig. 1. Dimensions of the quasi-static tensile specimen with a thickness of $1.2 \mathrm{~mm}$.

\section{Experimental procedure}

\subsection{Experimental material}

The chemical composition of the steel investigated in the present work is listed in Table 1 . A $150 \mathrm{~kg}$ ingot was produced in a vacuum induction melting furnace filled with argon, followed by hot rolling to a thickness of $3.5 \mathrm{~mm}$ between 900 and $1050{ }^{\circ} \mathrm{C}$, subsequently holding at $650^{\circ} \mathrm{C}$ for $1 \mathrm{~h}$ and cold rolling to $1.2 \mathrm{~mm}$. To obtain the optimal mechanical properties, Fe-10Mn-5Al-0.5C steel sheets were annealed at $850^{\circ} \mathrm{C}$ for $5 \mathrm{~min}$, then directly quenched into water. The density of these steel specimens, measured by the Archimedes drainage method, showed a reduction of $8.6 \%$ in comparison to the conventional high strength steel $\left(7.85 \mathrm{~g} \mathrm{~cm}^{-3}\right)$.

\subsection{Tensile test}

The quasi-static tensile properties were measured by the MTS809 universal material testing machine at the strain rate of $10^{-3} \mathrm{~s}^{-1}$. The specimens were designed as shown in Fig. 1. The tensile properties at the strain rate of $5 \mathrm{~s}^{-1}$ were studied using an intermediate strain rate tensile testing apparatus [16]. The schematic diagrams of the apparatus and the tensile specimen are presented in Fig. 2. The tensile testing at a strain rate range of 450 and $1200 \mathrm{~s}^{-1}$ was performed by using a dynamic tensile testing apparatus [17]. Figure 3 shows the schematic diagrams of the rotation disk bar-bar tensile impact apparatus and the corresponding tensile specimen. Three samples were used as repetitions in each set of experiments.

\subsection{Microstructure observation}

The specimens were polished and etched in a solution of $4 \%$ Nital. The microstructure observation was conducted by using an optical microscope (Nikon 
(a)
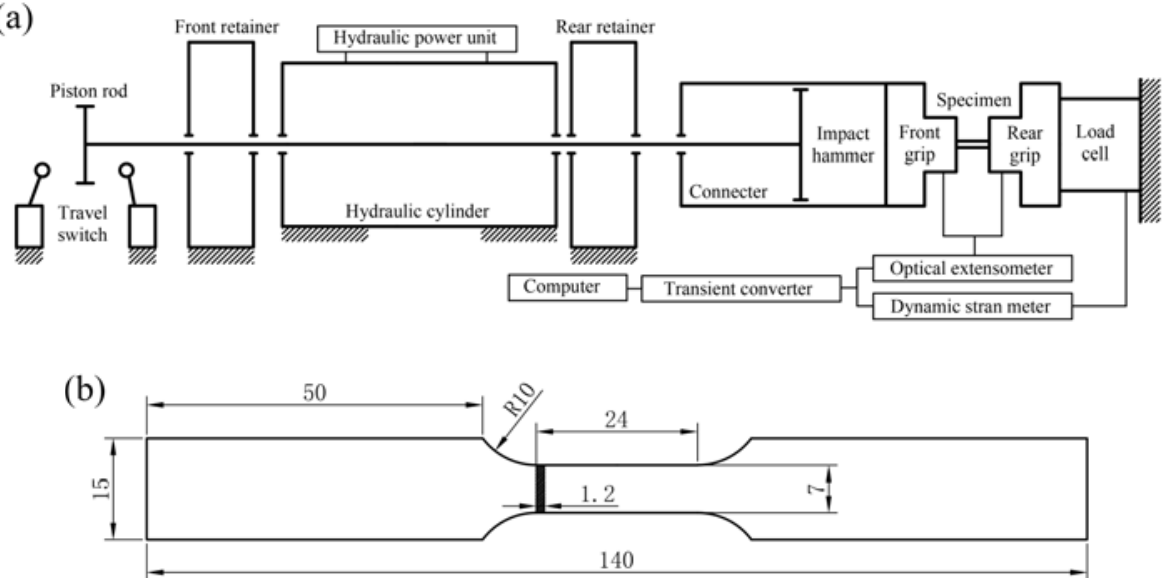

Fig. 2. Intermediate strain rate material testing: (a) schematic diagram of apparatus and (b) dimensions of specimens with a thickness of $1.2 \mathrm{~mm}$.

(a)

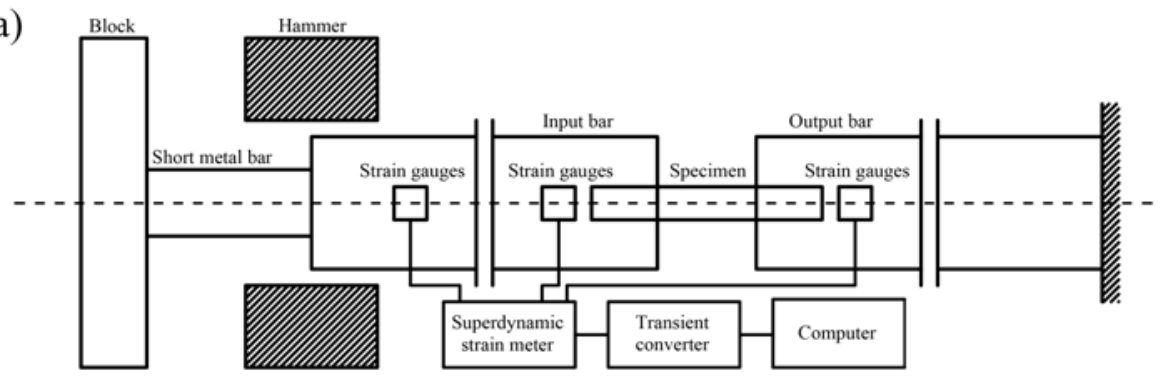

(b)

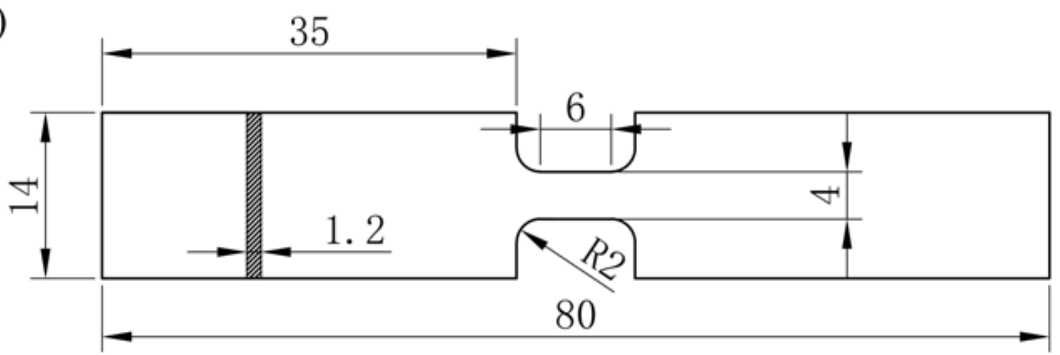

Fig. 3. Dynamic tensile specimen: (a) sketch of rotation disk bar-bar tensile impact apparatus; (b) dimensions of specimens with a thickness of $1.2 \mathrm{~mm}$.

MA100) and a scanning electron microscope (Hitachi S-570). X-ray diffraction (D/MAX-2500) operating at $40 \mathrm{kV}$ and $40 \mathrm{~mA}$ was also carried out to identify phases, using $\mathrm{Cu} \mathrm{K} \alpha$ radiation (scan rate $2^{\circ} \mathrm{min}^{-1}$, scan step size $0.02^{\circ}$ ). The volume fraction of austenite $\left(V_{\gamma}\right)$ was calculated by Eq. (1), according to Dyson et al. [18]:

$$
V_{\gamma}=\frac{1.4 I_{\gamma}}{I_{\alpha}+1.4 I_{\gamma}}
$$

where $I_{\gamma}$ is the average intensity of $220_{\gamma}$ and $331_{\gamma}$ diffraction peaks, and $I_{\alpha}$ is the intensity of $211_{\alpha}$ diffraction peak. A high-resolution transmission electron microscope (JEM-2010F) was operated at an acceleration voltage of $200 \mathrm{kV}$. TEM samples were cut into $3 \mathrm{~mm}$ diameter discs and mechanically polished to
$50 \mu \mathrm{m}$. Electropolishing was conducted using 5 vol.\% perchloric acid in ethanol at $-30^{\circ} \mathrm{C}$ in a twin jet electro polisher, with the electrical potential being set at $40 \mathrm{~V}$.

\section{Results and discussion}

\subsection{Microstructure}

Figure 4a exhibits the morphology of the steel investigated, where white ferrite embedded in dark gray or brown austenite matrix. It shows a strip-shaped microstructure. Moreover, measured by SEM\&EDS, the micrograph of the specimen is shown in Fig. 4b, where the island-like ferrite is observed in the austen- 
Table 2. Mechanical properties under the quasi-static condition of Fe-10Mn-5Al-0.5C steel

\begin{tabular}{cccc}
\hline $\begin{array}{c}\text { Yield strength } \\
(\mathrm{MPa})\end{array}$ & $\begin{array}{c}\text { Ultimate tensile strength } \\
(\mathrm{MPa})\end{array}$ & $\begin{array}{c}\text { Elongation } \\
(\%)\end{array}$ & $\begin{array}{c}\text { PSE } \\
(\mathrm{MPa} \%)\end{array}$ \\
\hline 654 & 886 & 41 & 36,326 \\
\hline
\end{tabular}
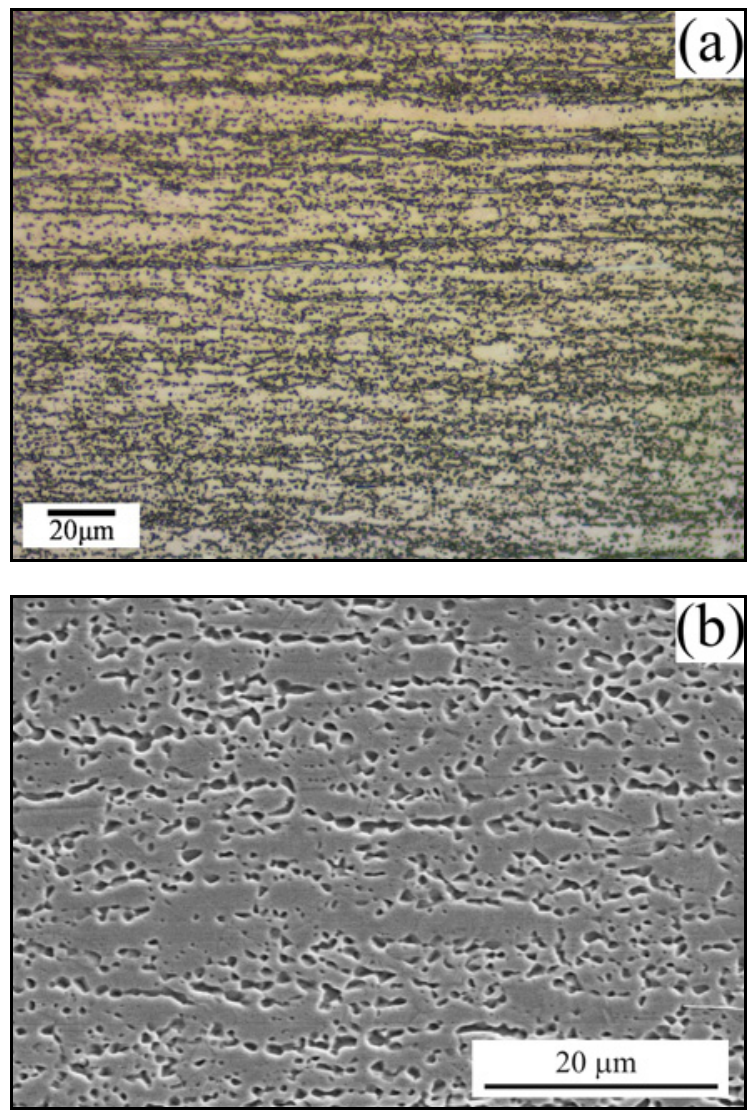

Fig. 4. Microstructure under: (a) OM micrograph and (b) SEM micrograph of steel.

ite matrix. Combined with quantitative metallography and X-ray diffraction analysis, the microstructure of Fe-10Mn-5Al-0.5C steel is composed of $27 \%$ of ferrite and $73 \%$ of austenite.

\subsection{Tensile properties of the steel under quasi-static loading conditions}

Figure 5 presents the room-temperature engineering stress-strain curve of Fe-10Mn-5Al-0.5C steel at a strain rate of $0.001 \mathrm{~s}^{-1}$, from which tensile properties are summarized in Table 2. From Fig. 5, it can be seen that the yield strength is $660 \mathrm{MPa}$, the ultimate tensile strength value is $886 \mathrm{MPa}$, and elongation is $41 \%$. The product of strength and elongation (PSE) of the steel investigated is more than $36,000 \mathrm{MPa} \%$. Fe-10Mn-5Al-0.5C steel has high strength and plas-

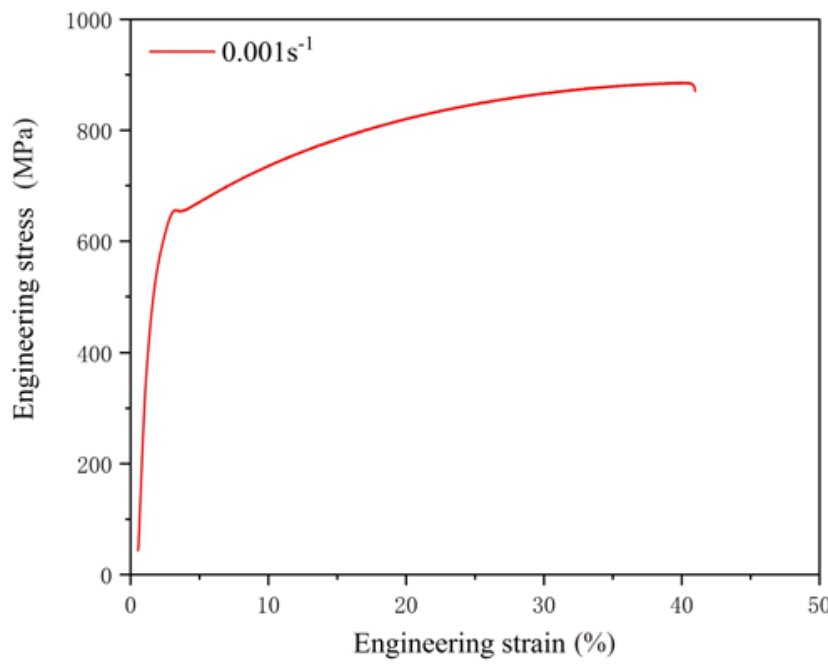

Fig. 5. Engineering stress-strain curves of the steel investigated under quasi-static conditions.

ticity and exhibits excellent combinations of specific strength and ductility. The fracture surface features of the steel tested under quasi-static conditions were observed using SEM, shown in Fig. 6. Isometry dimples can be seen in the specimen, and the fracture form is a typical microporous aggregated ductile fracture.

The XRD patterns of the steel specimens before and after the quasi-static tensile testing are shown in Fig. 7. The volume fraction of austenite $\left(V_{\gamma}\right)$ in the steel before tensile deformation is $73 \%$. However, the $V_{\gamma}$ in the deformed microstructure is $71 \%$. Only $2.7 \%$ of austenite produces phase transitions. It can be seen from Fig. 7 that the austenite with a volume fraction of $2 \%$ in Fe-10Mn-5Al-0.5C steel is transformed into deformation twins. The research outputs $[14,19$, 20] have shown that the deformation mechanism of austenite in steel is a main influential factor that determines steel properties. To study the strengthening mechanism of the steel investigated, it is necessary to calculate the stacking fault energy firstly.

In this study, the stacking fault energy of austenite in steel studied is calculated by Eq. (2), according to Olson et al. [21]:

$$
\mathrm{SFE}=2 \rho \Delta G_{\gamma \rightarrow \varepsilon}+2 \sigma_{\gamma / \varepsilon},
$$

where $\rho$ is the molar surface density determined by the $\{111\}$ plane lattice constant, $\Delta G_{\gamma \rightarrow \varepsilon}$ is the molar 

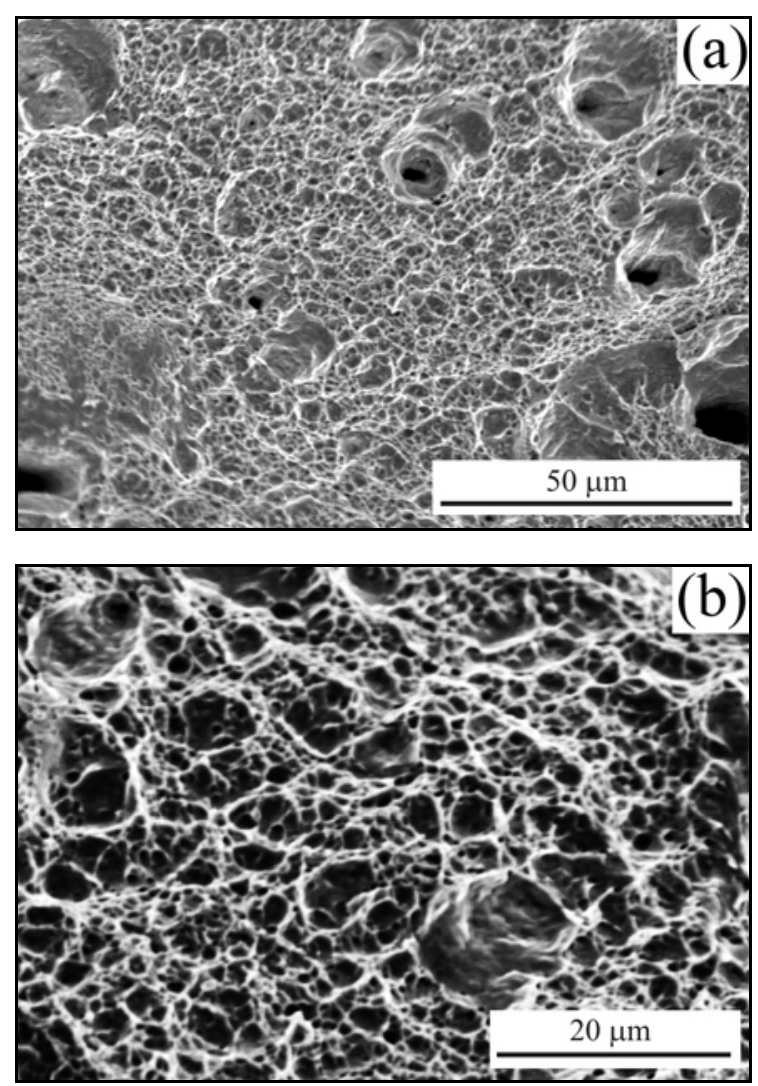

Fig. 6. SEM fracture morphology of Fe-10Mn-5Al-0.5C steel: (a) $1000 \times$; (b) $2000 \times$.

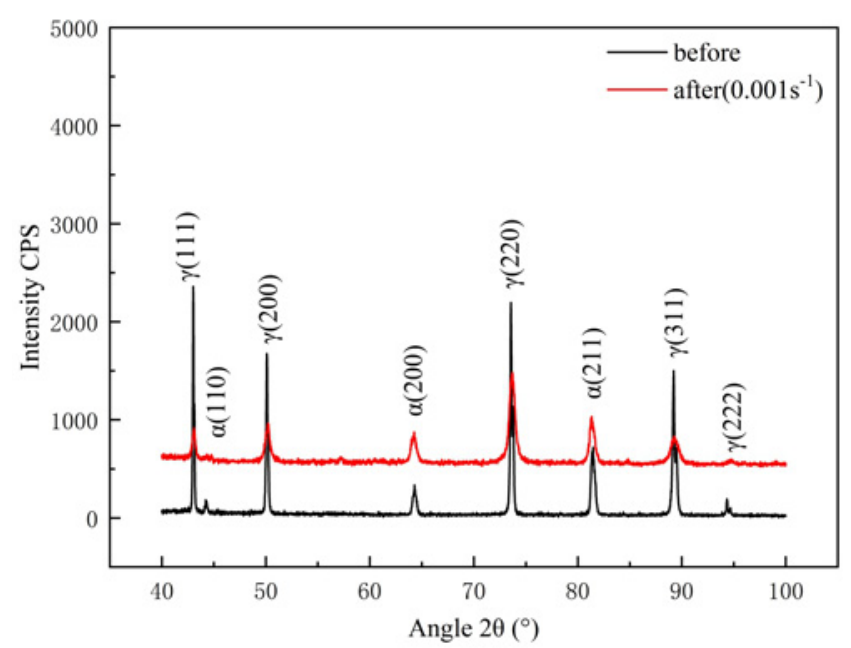

Fig. 7. X-ray diffraction results of the steel investigated before and after deformation.

Gibbs energy of the $\gamma \rightarrow \varepsilon$ phase transition, $\sigma_{\gamma / \varepsilon}$ is the $\gamma / \varepsilon$ interface energy, which is $10 \mathrm{~mJ} \mathrm{~m}^{-2}$. Based on the regular solution model, $\Delta G^{\gamma \rightarrow \varepsilon}$ can be calculated using the equation given below [22]:
$\Delta G^{\gamma \rightarrow \varepsilon}=\Delta G_{\mathrm{chem}}^{\gamma \rightarrow \varepsilon}+\Delta G_{\mathrm{mag}}^{\gamma \rightarrow \varepsilon}+\Delta G_{\mathrm{seg}}^{\gamma \rightarrow \varepsilon}+\Delta G_{\mathrm{ex}}$

where $\Delta G_{\text {chem }}^{\gamma \rightarrow \varepsilon}$ is the molar thermochemical Gibbs free energy difference between $\gamma$ and $\varepsilon, \Delta G_{\mathrm{mag}}^{\gamma \rightarrow \varepsilon}$ is the contribution from the magnetic transition energy, $\Delta G_{\mathrm{ex}}$ is the excess of free energy due to the grain size and $\Delta G_{\mathrm{seg}}^{\gamma \rightarrow \varepsilon}$ is the free energy difference due to the Suzuki effect between $\gamma$ and $\varepsilon$. The chemical composition of austenite in the Fe-10Mn-5Al-0.5C steel sheet after holding at $1123 \mathrm{~K}$ for a while was calculated by Software Thermo-Calc using the TCFE9 database. The stacking fault energy of austenite in the steel calculated by Eqs. (2) and (3) is $45 \mathrm{~mJ} \mathrm{~m}^{-2}$. The previous research work $[14,19,20]$ showed that, when the stacking fault energy was less than $20 \mathrm{~mJ} \mathrm{~m}^{-2}$, the martensitic transformation was the main deformation mechanism; when the stacking fault energy was in the range of $20-40 \mathrm{~mJ} \mathrm{~m}^{-2}$, it tended to obtain high strength, high plasticity, and high strain hardening rate by forming mechanical twinning; when the stacking fault energy is higher than $55 \mathrm{~mJ} \mathrm{~m}^{-2}$, the deformation mechanism is MBIP effect dominant [23]. While the stacking fault energy was in the range of 40-55 $\mathrm{mJ} \mathrm{m}^{-2}$, the MBIP effect and TWIP effect coincided. In this study, the stacking fault energy of the steel studied is in the range of $40-55 \mathrm{~mJ} \mathrm{~m}^{-2}$, which should be dominated by the MBIP effect and TWIP effect.

It can be seen in Fig. 8 that the austenite in Fe$-10 \mathrm{Mn}-5 \mathrm{Al}-0.5 \mathrm{C}$ steel is transformed into a micro band and deformation twin during the tensile deformation process at the strain rate of $10^{-3} \mathrm{~s}^{-1}$. The appearance of micro band and deformation twin in the microstructure of the specimen after tensile deformation illustrates the existence of the MBIP effect and TWIP effect indeed, which is consistent with the calculation results of the stacking fault energy. It is also due to the MBIP effect and TWIP effect in austenite that the steel has high strength, high elongation, and excellent comprehensive performance.

\subsection{Tensile properties under dynamic loading conditions}

The engineering stress-strain curves of the steel investigated at different strain rates are shown in Fig. 9. The mechanical properties of the steel are listed in Table 3 . With the increase of strain rate from 0.001 to $1200 \mathrm{~s}^{-1}$, the tensile strength of the steel is increased from 886 to $1015 \mathrm{MPa}$. This is attributed to the large multiplication of dislocations in a short deformation time that makes the dislocation sliding difficult at the higher strain rate [24]. However, with the increase of strain rate from 0.001 to $1200 \mathrm{~s}^{-1}$, the elongation of the steel studied is initially decreased from 41 to $16 \%$ and then increases from 16 to $25 \%$. At a strain rate of $450 \mathrm{~s}^{-1}$, the 
Ta ble 3. Mechanical properties at a different strain rate of Fe-10Mn-5Al-0.5C steel

\begin{tabular}{ccccc}
\hline $\begin{array}{c}\text { Strain rate } \\
\left(\mathrm{s}^{-1}\right)\end{array}$ & $\begin{array}{c}\text { Yield strength } \\
(\mathrm{MPa})\end{array}$ & $\begin{array}{c}\text { Ultimate tensile strength } \\
(\mathrm{MPa})\end{array}$ & $\begin{array}{c}\text { Elongation } \\
(\%)\end{array}$ & $\begin{array}{c}E_{\mathrm{ab}} \\
(\mathrm{MPa} \%)\end{array}$ \\
\hline 0.001 & 654 & 886 & 41 & 32,065 \\
5 & 748 & 925 & 31 & 25,951 \\
450 & 829 & 983 & 16 & 14,005 \\
1200 & 851 & 1015 & 25 & 23,487 \\
\hline
\end{tabular}
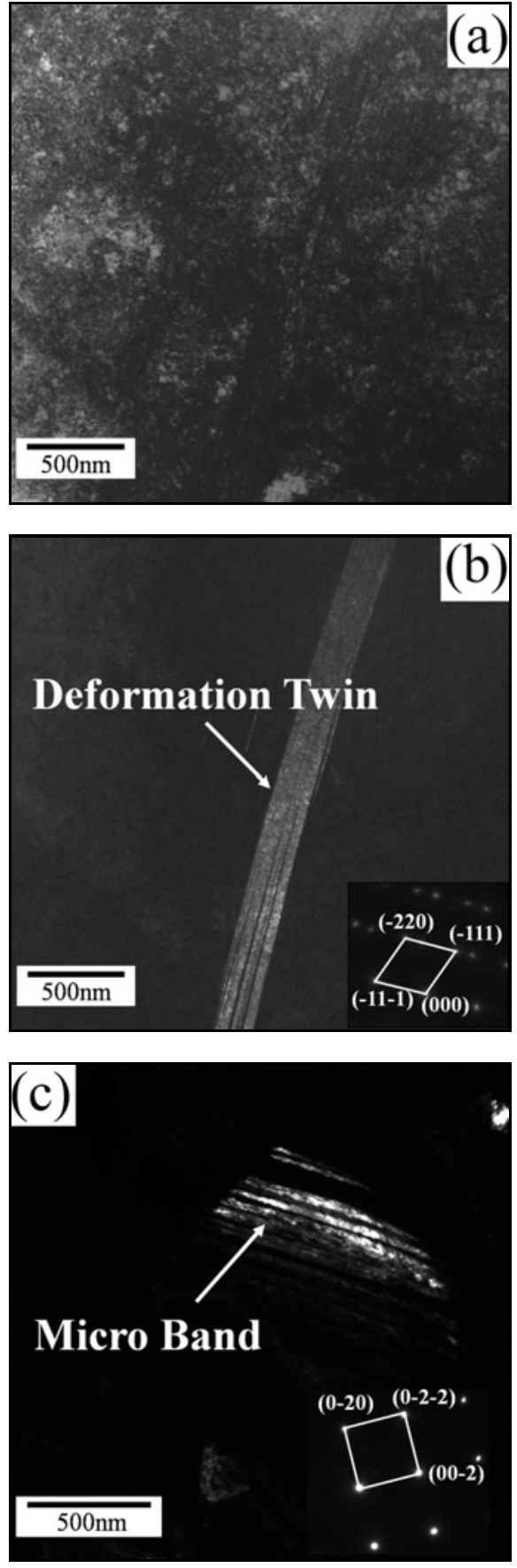

Fig. 8. TEM analysis of Fe-10Mn-5Al-0.5C steel after deformation under the quasi-static condition: (a) bright field, (b) deformation twin and diffraction pattern, and (c) micro band and diffraction pattern.

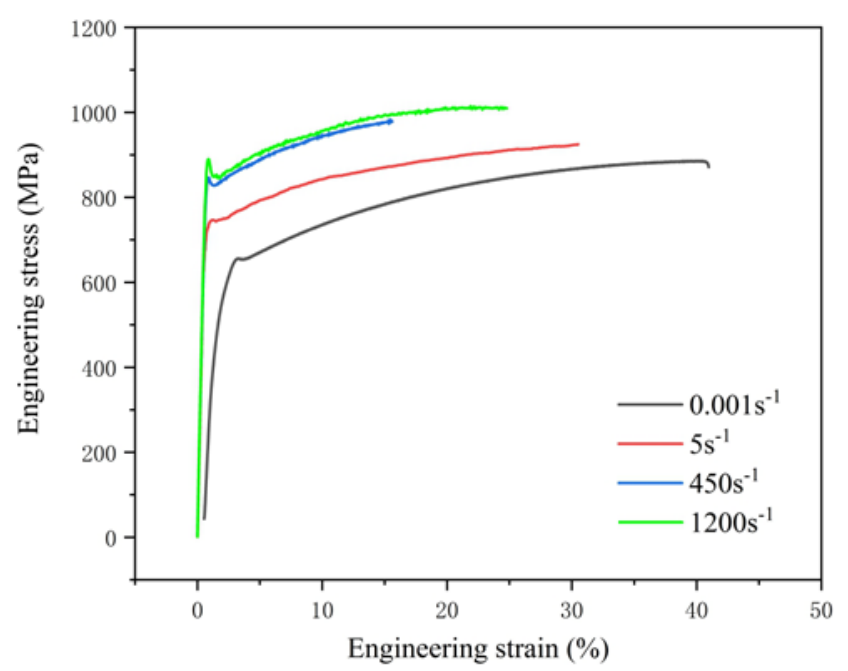

Fig. 9. The tensile stress-strain curve at a different strain rate of $\mathrm{Fe}-10 \mathrm{Mn}-5 \mathrm{Al}-0.5 \mathrm{C}$ steel.

elongation is minimal. It can be concluded that the plasticity-increasing effects in austenite induced by a micro band and deformation twin are suppressed by the deformation localization at a high strain rate [25]. As the strain rate increases to $1200 \mathrm{~s}^{-1}$, it can be seen that the uniform elongation starts to increase. The possible reason is the softening of the matrix caused by adiabatic heating. Adiabatic temperature can be calculated by Eq. (4), according to Curtze et al. [14]:

$$
\Delta T=\frac{\Delta Q}{\rho C_{\mathrm{P}}}=\frac{\beta}{\rho C_{\mathrm{P}}} \int_{\varepsilon_{1}}^{\varepsilon_{2}} \sigma \mathrm{d} \varepsilon,
$$

where $\sigma(\mathrm{Pa})$ and $\varepsilon$ indicate stress and strain, $\rho$ $\left(\mathrm{kg} \mathrm{m}^{-3}\right)$ is density, $C_{\mathrm{P}}\left(\mathrm{J} \mathrm{kg}^{-1} \mathrm{~K}^{-1}\right)$ is heat capacity, $\Delta T(K)$ is temperature rise, and $\beta$ is the efficiency of the thermomechanical conversion. At a strain rate of $1200 \mathrm{~s}^{-1}, \Delta T$ is $63 \mathrm{~K}$. Some related research [26] has shown that during deformation of AHSS (Advanced High Strength Steel), due to the changed work of plastic deformation and the latent heat caused by the phase transformation of the retained austenite, the temperature in the necking zone exceeds $80^{\circ} \mathrm{C}$ at a strain rate of $0.1 \mathrm{~s}^{-1}$. Calculation results show that temperature at a strain rate of $1000 \mathrm{~s}^{-1}$ increases almost by $100^{\circ} \mathrm{C}$. If the necking stage is considered, it 


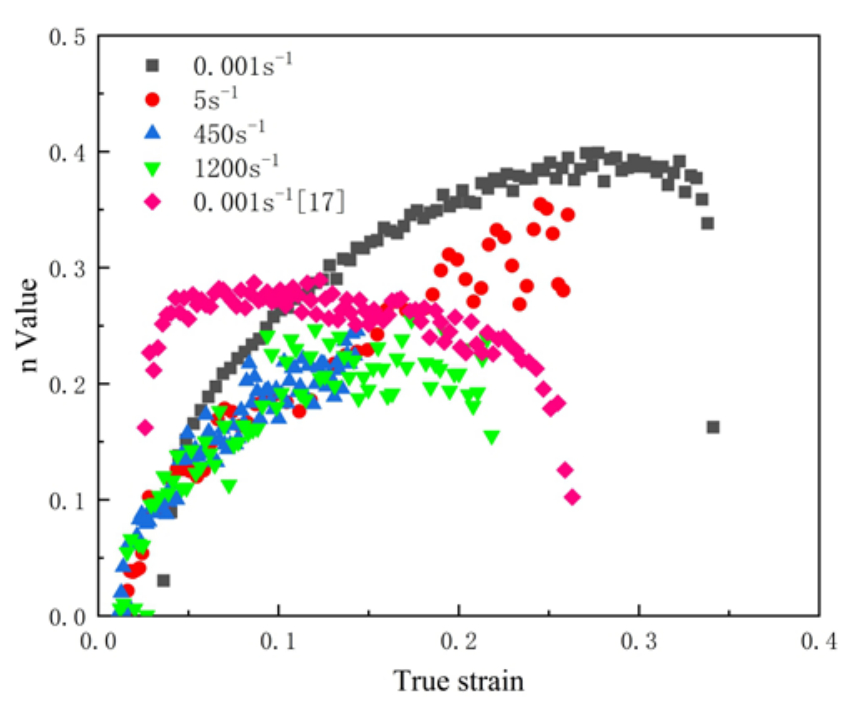

Fig. 10. Instantaneous strain hardening exponent at a strain rate of $0.001,5,450$, and $1200 \mathrm{~s}^{-1}$.

could increase locally to over $300^{\circ} \mathrm{C}$. For that reason, the adiabatic heating has influenced the ductility of the steel tested significantly by softening of matrix and changing deformation mechanisms [2729].

The change of the deformation mechanisms was attributed to the temperature dependence of both the driving force of the martensitic $\gamma \rightarrow \varepsilon$ transformation and the stacking fault energy of the austenite [29]. According to Eqs. (2) and (3), when the temperature increases by $63 \mathrm{~K}$, the stacking fault energy increases by $13 \mathrm{~mJ} \mathrm{~m}^{-2}$. The MBIP effect and TWIP effect will be suppressed. It is noted that the elongation of the steel at the strain rate of $1200 \mathrm{~s}^{-1}$ is always lower than that at the quasi-static condition. The reason is that the loss of ductility resulting from the deformation localization and the weakness of the MBIP effect and TWIP effect are much higher than the benefit of ductility resulted from the softening of matrix caused by adiabatic heating.

For some automotive components, the ability to absorb energy is an important measurement index. In this research, integral areas of tensile curves are used to evaluate the capability of energy absorption [30], which are shown in Table 3 . It can be seen that compared with the quasi-static condition, the ultimate tensile strength of Fe-10Mn-5Al-0.5C steel at a strain rate of 5,450 , and $1200 \mathrm{~s}^{-1}$ is increased by $4.4,10.9$, and $14.6 \%$, respectively, however, elongation reduced by $24.4,61.0$, and $39.0 \%$ and energy absorption reduced by $19.1,56.3$, and $26.8 \%$, respectively. It seems that at a strain rate of $450 \mathrm{~s}^{-1}$, the energy absorption capacity of Fe-10Mn-5Al-0.5C steel is the lowest.

Figure 10 is the curve of instantaneous strain hardening exponent ( $n$-value) with strain at different strain rates. The $n$-value was obtained by Hollomon equation [31]:

$$
\sigma=K \varepsilon^{n}
$$

where $\sigma$ is the true stress, $\varepsilon$ is the true strain, $K$ is the strength coefficient, and $n$ is the strain hardening exponent. It can be seen from the figure that in all deformation processes of Fe-10Mn-5Al-0.5C steel, the value of $n$ increases from small to large, indicating that the dislocations in the material increase rapidly and the strain hardening effect becomes high. After the strain hardening value reaching a maximum, breakage occurs, while in [17], the strain hardening exponent ( $n$-value) of TRIP steel is almost in a constant state. It is because during the deformation process of the material, there is also stress relaxation at the same time of phase transformation strengthening, resulting in high plasticity. Although both Fe-10Mn-5Al$0.5 \mathrm{C}$ steel and TRIP steel have austenite, the austenite in Fe-10Mn-5Al-0.5C steel is mostly transformed to micro band and does not transform to another crystal structure. So the austenite in Fe-10Mn-5Al$0.5 \mathrm{C}$ steel cannot provide progressive phase transition. More than this, the strain hardening exponent ( $n$ value) of DP (Dual Phase) steel decreases with strain increasing because of lacking phase transition in [32]. The research on the instantaneous strain hardening exponent is very little. More research is needed to explore the mechanism of instantaneous strain hardening exponent change. By comparing the strain hardening values at different strain rates, it is found that the strain hardening value decreases as the strain rate increases, which is consistent with the conclusion of [33], and because the $n$-value decreases, the sample would be broken before significant geometric necking occurred.

\section{Conclusions}

In this study, the influence of strain rate on the microstructure and mechanical properties of Fe-0.5C$-10 \mathrm{Mn}-5 \mathrm{Al}$ steel has been studied in detail. Based on the research outcomes, the following conclusions can be drawn:

(1) Fe-0.5C-10Mn-5Al steel has a high tensile strength $(886 \mathrm{MPa})$ and plasticity $(41 \%)$. It exhibits excellent combinations of specific strength and ductility (more than $36,000 \mathrm{MPa} \%$ ) at a strain rate of $0.001 \mathrm{~s}^{-1}$ after annealing at $850{ }^{\circ} \mathrm{C}$ for $5 \mathrm{~min}$, then directly quenching into water.

(2) With the increase of a strain rate from 0.001 to $1200 \mathrm{~s}^{-1}$, the tensile strength of the steel is increased from 886 to $1015 \mathrm{MPa}$, while the elongation is initially decreased from 41 to $16 \%$, and then increases from 16 to $25 \%$. At the strain rate of $450 \mathrm{~s}^{-1}$, the elongation 
is minimal, and the energy absorption capacity is the lowest.

(3) With the deformation progresses, the value of $n$ increases from small to large, the strain hardening effect becomes high. Comparing with TRIP steel, the austenite in Fe-10Mn-5Al-0.5C steel is most transformed to a micro band and cannot provide a progressive phase transition.

\section{Acknowledgements}

This work was financially supported by the National Key R\&D Program of China under Grant 2017YFB03044 02 and the Natural Science Research Foundation of China (No. 51801015)

\section{References}

[1] O. A. Zambrano, A general perspective of Fe-Mn-Al-C steels, J Mater Sci 53 (2018) 14003-14062. doi:10.1007/s10853-018-2551-6

[2] Y. Lee, C. Choi, Driving force for $\gamma \rightarrow \varepsilon$ martensitic transformation and stacking fault energy of $\gamma$ in Fe-Mn binary system, Metall Mater Trans A 31 (2000) 355-360. doi:10.1007/s11661-000-0271-3

[3] G. Dini, A. Najafizadeh, S. M. Monir-Vaghefi, R. Ueji, Grain size effect on the martensite formation in a high-manganese TWIP steel by the Rietveld method, J Mater Sci Technol 26 (2010) 181-186. doi:10.1016/S1005-0302(10)60030-8

[4] A. Dumay, J. P. Chateau, S. Allain, S. Migot, O. Bouaziz, Influence of addition elements on the stacking fault energy and mechanical properties of an austenitic Fe-Mn-C steel, Mater Sci Eng A 483-484 (2008) 184187. doi:10.1016/j.msea.2006.12.170

[5] B. Mahato, S. K. Shee, T. Sahu, S. Ghosh Chowdhury, P. Sahu, D. A. Porter, L. P. Karjalainen, An effective stacking fault energy viewpoint on the formation of extended defects and their contribution to strain hardening in a $\mathrm{Fe}-\mathrm{Mn}-\mathrm{Si}-\mathrm{Al}$ twinninginduced plasticity steel, Acta Mater 86 (2015) 69-79. doi:10.1016/j.actamat.2014.12.015

[6] F. Georg, B. Udo, Microstructures and mechanical properties of high-strength Fe-Mn-Al-C light-weight TRIPLEX steels, Steel Res Int 77 (2006) 627-633. doi:10.1002/srin.200606440

[7] J. D. Yoo, K.-T. Park, Microband-induced plasticity in a high Mn-Al-C light steel, Mater Sci Eng A 496 (2008) 417-424. doi:10.1016/j.msea.2008.05.042

[8] J. D. Yoo, S. W. Hwang, K. T. Park, Origin of extended tensile ductility of a Fe-28Mn-10Al-1C steel, Metall Mater Trans A 40 (2009) 1520-1523. doi:10.1007/s11661-009-9862-9

[9] J. D. Yoo, S. W. Hwang, K. T. Park, Factors influencing the tensile behavior of Fe-28Mn-9Al-0.8C steel, Mater Sci Eng A 508 (2009) 234-240. doi:10.1016/j.msea.2008.12.055

[10] I. Gutierrez-Urrutia, D. Raabe, Microbanding mechanism in a Fe-Mn-C high-Mn twinning-induced plasticity steel, Scripta Mater 69 (2013) 53-56. doi:10.1016/j.scriptamat.2013.03.010
[11] Z. Wang, H. Bei, I. Baker, Microband induced plasticity and the temperature dependence of the mechanical properties of a carbon-doped FeNiMnAlCr high entropy alloy, Mater Charact 139 (2018) 373-381. doi:10.1016/i.matchar.2018.03.017

[12] Z. Y. Tang, J. N. Huang, H. Ding, Z. H. Cai, R. D. K. Misra, On the dynamic behavior and relationship to mechanical properties of cold-rolled Fe-0.2C-15Mn$-3 \mathrm{Al}$ steel at intermediate strain rate, Mater Sci Eng A 742 (2019) 423-431. doi:10.1016/j.msea.2018.11.039

[13] J. Park, M. Kang, S. S. Sohn, S. H. Kim, H. S. Kim, N. J. Kim, S. Lee, Quasi-static and dynamic deformation mechanisms interpreted by microstructural evolution in Twinning Induced Plasticity (TWIP) steel, Mater Sci Eng A 684 (2017) 54-63. doi:10.1016/j.msea.2016.12.037

[14] S. Curtze, V. T. Kuokkala, Dependence of tensile deformation behavior of TWIP steels on stacking fault energy, temperature and strain rate, Acta Mater 58 (2010) 5129-5141. doi:10.1016/j.actamat.2010.05.049

[15] Y. Ha, H. Kim, K. H. Kwon, S.-G. Lee, S. Lee, N J. Kim, Microstructural evolution in Fe-22Mn-0.4C twinning-induced plasticity steel during high strain rate deformation, Metall Mater Trans A 46 (2014) 545-548. doi:10.1007/s11661-014-2705-3

[16] H. Wu, G. Ma, Y. Xia, Experimental study of tensile properties of PMMA at intermediate strain rate, Mater Lett 58 (2004) 3681-3685. doi:10.1016/j.matlet.2004.07.022

[17] Z. He, Y. He, Y. Ling, Q. Wu, Y. Gao, L. Li, Effect of strain rate on deformation behavior of TRIP steels, J Mater Process Technol 212 (2012) 2141-2147. doi:10.1016/j.jmatprotec.2012.05.020

[18] D. J. Dyson, Effect of alloying additions on the lattice parameter of austenite, J Iron Steel Inst 208 (1970) 469-474.

[19] S. Allain, J. P. Chateau, O. Bouaziz, A physical model of the twinning-induced plasticity effect in a high manganese austenitic steel, Mater Sci Eng A 387-389 (2004) 143-147. doi:10.1016/j.msea.2004.01.060

[20] S. Allain, J. P. Chateau, O. Bouaziz, S. Migot, N. Guelton, Correlations between the calculated stacking fault energy and the plasticity mechanisms in Fe-MnC alloys, Mater Sci Eng A 387-389 (2004) 158-162. doi:10.1016/j.msea.2004.01.059

[21] G. B. Olson, M. Cohen, A general mechanism of martensitic nucleation Part I. General concepts and the FCC $\rightarrow$ HCP transformation, Metall Trans A 7A (1976) 1897-1904. doi:10.1007/BF02659822

[22] O. A. Zambrano, Stacking fault energy maps of Fe-Mn-Al-C-Si steels: Effect of temperature, grain size, and variations in compositions, J Eng Mater-T ASME 138 (2016) 1-9. doi:10.1115/1.4033632

[23] F. Yang, R. Song, T. Sun, L. Zhang, C. Zhao, B. Liao, Microstructure and mechanical properties of Fe-Mn-Al light-weight high strength steel, Acta Metall Sin 50 (2014) 897-904. doi:10.11900/0412.1961.2013.00850

[24] K. Ryttberg, M. Knutson Wedel, P. Dahlman, L. Nyborg, Microstructural evolution during fracture induced by high strain rate deformation of $100 \mathrm{Cr} 6$ steel, J Mater Process Technol 209 (2009) 3325-3334. $\underline{\text { doi:10.1016/j.jmatprotec.2008.07.056 }}$ 
[25] R. Colás, A. Grinberg, A study of strain localization by means of reduced gauge compression testing, J Mater Process Technol 88 (1999) 276-283. doi:10.1016/s0924-0136(98)00406-3

[26] Z. Gronostajski, A. Niechajowicz, R. Kuziak, J. Krawczyk, S. Polak, The effect of the strain rate on the stress-strain curve and microstructure of AHSS, J Mater Process Technol 242 (2017) 246-259. doi:10.1016/i.jmatprotec.2016.11.023

[27] Y. Gao, C. Xu, Z. He, Y. He, L. Li, Response characteristics and adiabatic heating during high strain rate for TRIP steel and DP steel, J Iron Steel Res Int 22 (2015) 48-54. doi:10.1016/s1006-706x(15)60008-5

[28] X. Li, L. Chen, Y. Zhao, R. D. K. Misra, Influence of manganese content on $\varepsilon$ - $/ \alpha^{\prime}$-martensitic transformation and tensile properties of low-C high-Mn TRIP steels, Materials Design 142 (2018) 190-202. doi:10.1016/j.matdes.2018.01.026

[29] S. Martin, S. Wolf, U. Martin, L. Krüger, D. Rafaja, Deformation mechanisms in austenitic TRIP/TWIP steel as a function of temperature, Metall Mater Trans A 47 (2014) 49-58. doi:10.1007/s11661-014-2684-4
[30] M. Kang, J. Park, S. S. Sohn, D. H. Ahn, H. S. Kim, W. T. Cho, K. G. Chin, S. Lee, Dynamic tensile behavior of twinning-induced plasticity/low-carbon (TWIP/LC) steel clad sheets bonded by hot rolling, Mater Sci Eng A 700 (2017) 387-396. doi:10.1016/j.msea.2017.06.003

[31] J. H. Hollomon, J. Member, Tensile deformation, Trans Metall Soc AIME 162 (1945) 268-290.

[32] P. J. Jacques, Q. Furnemont, F. Lani, T. Pardoen, F. Delannay, Multiscale mechanics of TRIP-assisted multiphase steels: I. Characterization and mechanical testing, Acta Mater 55 (2007) 3681-3693. doi:10.1016/j.actamat.2007.02.029

[33] C. Tang, J. Zhu, Y. Zhang, H. Zhou, Effect of strain rate on strain hardening exponent of some metallic materials, Acta Metall Sin 7 (1994) 183-186. 